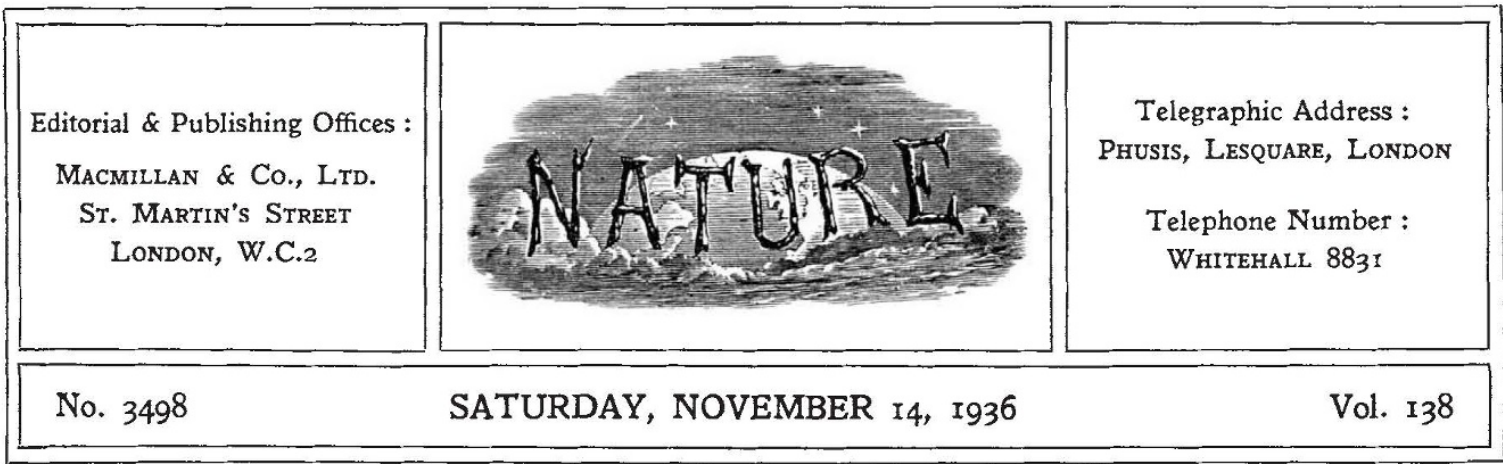

\title{
Outlook of Professional Organizations
}

PR ROFOUND changes in manufacturing technique and industrial organization have resulted from the modernization of industry under the influence of power production during the last twenty years. This is generally recognized, but equally important changes in the personnel of industry have largely escaped attention. The recent report of the Industrial Health Research Board, it is true, pointed out that industry is demanding a different type of worker, but apart from Prof. Carr-Saunders' and Mr. P. A. Wilson's study of the professions, the increasing importance of the technical and scientific worker in industry has scarcely received the attention it deserves. Not only have the technical and scientific staffs been immediately responsible for much of the development and reorganization involved in the modernization and rationalization of industry, but they have also assumed an increasing share of the responsibility for the administration of the larger industrial units characteristic of to-day. In fact, large-scale industry mainly depends on their activities, and in turn they find in it the fullest scope for their knowledge and skill.

The rise of virtually a new professional class or type in this way is one of the most significant results of the modern technique in industry and commerce; and its social consequences have as yet been given little attention. Certain of these questions are considered in a paper by Mr. S. W. Smith on the place and function of the administrative and technical worker in the new forms of economic structure, presented to Section F (Economic Science and Statistics) at the British Association meeting at Blackpool. One of the most important of these changes is the way in which the functional and professional outlook in the direction of industry is replacing the purely speculative or profit-seeking motive.

This growing power of the vocational outlook is of fundamental importance in the adaptation of industry, and indeed of society to meet new conditions. In so far as industry and commerce are directed less by self-interest than by the spirit of trusteeship or stewardship and service, the dangers of exploitation and social friction tend to diminish. Moreover, the type of control required in industry to-day involves leadership rather than domination, without sacrificing authority; discipline based on intelligent co-operation, and decision reflecting the ideas of trained personnel acting freely and willingly in unity rather than the arbitrary will of a functional head.

That in certain public utility corporations the directors should, contrary to prevailing practice in limited companies, be debarred from any holding of shares, so as to secure that their dominant concern should be with the public interest, is only one example of the way in which a sense of duty and responsibility is replacing purely financial or private interests in the conduct of large undertakings. Moreover, the professional man, whether engaged in administrative work or not, finds his chief interest, when reasonably paid, in his work for its own sake; and while the professional ideal continues to pervade the control of industry, so we may expect to find the service motive increasing in influence, and professional pride in the proper and efficient conduct of business organizations strongly reinforced.

This in itself should facilitate the wider outlook which to-day is essential in the integration of 
society to meet the impact of science. Industry can no longer be conducted solely with reference to its own internal efficiency and economy. It has to be considered in relation to society as a whole, and the technical ideal of fitness for a purpose must be applied in even wider spheres. No longer can we be content with a purely financial or even physical concept of the principle of economy. Social and human values are equally concerned, and industrial efficiency to-day involves the consideration not merely of chemical and physical processes but also of industrial health, psychology and the repercussions of a development on the community. What the product and process contribute to the worker and to the community are as important as what the worker contributes to the product.

The entrepreneur spirit alone is entirely inadequate to deal with such a situation and the creative forces involved. On the other hand, those scientific and technical workers whose administrative capacity and technical knowledge have placed them in such positions of trust have not invariably proved equal to the moral responsibilities involved. To this, particular attention was directed in Prof. W. Cramp's forceful address to Section G (Engineering) at the British Association. While the legal liabilities of the engineer and the loss of prestige attaching to faulty design or workmanship are the final safeguard to the community against abuse of privilege, standards of professional conduct are not infrequently honoured in the breach rather than by observance under the stress of commercial conditions.

For this, two factors may be regarded as primarily responsible. In the first place, as the instances cited by Prof. Cramp show, there is the absence of a scale of values firmly accepted by technical and scientific workers and so established by training and tradition that violation almost inevitably involves disqualification from practice. In part, this is a matter of education; in part, a question of organization. One of the main motives, in faet, in attempts to raise the status of the chemist or the engineer by establishing a legal register and closing the profession has been that of safeguarding the public from the dangers attending a low standard of professional competence or integrity.

In the second place, the disregard of professional standards of rectitude is often due to the absence of a professional organization strong enough to afford its members adequate support in the face of economic or other forms of pressure from any source which tempts them to disregard the accepted ethical code. Nothing is more important to-day than that professional workers, whether within the ranks of science or not, should give their primary loyalty to their professional or vocational associations, and not to commercial or industrial organizations. It is only as they find in vocational organizations their permanent anchor. age and shelter that professional workers can hope to make their full contribution to the shaping of organizations into instruments for the service of society and not for its mastery or exploitation.

This is indeed our crucial problem. The same factors that have increased the numbers of technical and professional workers have diminished their economic security and undermined their independence. The incidence of unemployment among their ranks on a scale undreamed of, in a class which was before the War virtually immune, has made efficient and effective professional associations essential if the full independent contribution of the professional worker is to be secured. The last fifteen years or so have witnessed a remarkable increase in the establishment of protective associations among such workers, and already an appreciable number of such organizations have negotiated collective agreements or enjoy the benefit of Whitley councils.

As yet, however, there have been few signs that such professional associations have recognized the wide orbit of their social responsibilities, nor have many of them yet advanced to a stage when they can afford a standard of professional protection commensurate with the pressure which industrial organization to-day could bring to bear if it chose. Nothing is more important than that professional organizations should address themselves to this question and consider their real place both in industry and in society to-day. Only as the professional worker gains his full independence can he make his decisive contribution to the shaping of society. Only, however, as he realizes the magnitude of that contribution is he likely to constrain the multiplicity of professional associations which at present prevents professional unity, for example, among chemists, from acting together in some way adequate to afford the members of the profession the necessary full protection.

The question of the responsibility of scientific workers for the prostitution of scientific effort for purposes of warfare, to which such repeated 
attention has been given of late, is only a special but rather difficult case. It is the absence of an association of scientific workers with any effective professional code, and the weakness of the professional ties between scientific workers in different countries, which debilitate any action by scientific workers at present. While, however, for the present it is rather as individual citizens than professional men that chemists and scientific workers in general can throw their weight into the scale against the tendencies which are dragging science and civilization down and debasing our heritage of intellectual and spiritual values, the recoil from the present abuse of scientific know. ledge should surely inspire some determined effort to organize professional associations.

No thoughtful person can be blind to the dangers which the present abuse of scientific effort offers to science itself as to all that is best in our civilization. It is unthinkable that scientific workers should be so deluded or perverse as to make no attempt to preserve even the integrity of their own vocation. Towards this the first step is adequate professional organization. If that is undertaken in no mean spirit, but in a wide vision of the part which free scientific workers might play in the world of affairs, the petty loyalties and short-sightedness which in the past have prevented professional unity will surely disappear. Instead, we may see different classes of scientific workers, firmly established in their respective professional associations, presenting a united front and using their freedom to serve the community by shaping its organization in accordance with a nobler and wider concept of society. So, too, we shall find the sense of dependence and oppression which multiply so rapidly in the totalitarian State being lifted from the shoulders of men, and a measure of freedom, dignity and responsibility being given to them which once more shall prove the stimulus to creative thought, and add to the spiritual heritage of mankind.

\section{World Population}

World Population:

Past Growth and Present Trends. By A. M. CarrSaunders. (Published under the auspices of the Royal Institute of International Affairs.) Pp. xv +336. (Oxford: Clarendon Press ; London: 0xford University Press, 1936.) 12s. 6d. net.

THE public is being very well provided with information on the admittedly important subject of population; its growth and possible decline; its age constitution and the changes of that factor; the probable lengths of our lives; the social causes and effects of changes in the birth-and death-rates ; migration and the future of the European races. Quite recently there have appeared several important works in English dealing with these matters, or some of them, such as, "Length of Life, a Study of the Life Table", by Dublin and Lotka ; "The Measurement of Population Growth", by R. R. Kuczynski ; "The Struggle for Population", by D. V. Glass, and now the important book under review.

Prof. Carr-Saunders is one of our most distinguished authorities on the subject. He was early in the field with his well-known study, "The Population Problem", which was published fourteen years ago and is still a mine of useful information. His new book is presented in a more popular guise and brings the facts up to date. These fourteen years have seen a great increase in the interest of the public in all population questions. One can scarcely take up a newspaper without seeing in it some letter or article on population. It is clear that the public in most Western countries is alive to its importance. There is evidence of this not only in the columns of the Press, but also in the foundation, some nine years ago, of the International Population Union and its constituent body in Great Britain, the British Population Society; in the various congresses that have been held in Geneva, in London, in Berlin; in the announcement of the Population Congress which is to take place in Paris next year; and quite recently, in the appointment, by the Eugenics Society, of a committee to investigate the fall of the birth-rate in Great Britain. All this apparatus, and the books mentioned above, will serve to keep the public provided with reliable information about these vitally important, and, in certain aspects, difficult matters.

In the author's own words, his book "attempts, though very briefly, to reconstruct population history and to describe the present population situation." He naturally begins with some account of the sources of information, and describes the early enumerations for special purposes, the 